\title{
A Note on the Insecticide Susceptibility Status of Disease Vectors; Anopheles sundaicus and Aedes albopictus, in the Car Nicobar Island
}

\author{
${ }^{1}$ Zahid Ali Khan, ${ }^{2}$ I. P. Sunish \\ ${ }^{1}$ Research Scholar, Regional Medical Research Centre (ICMR), PB No. 13, Port Blair, Andaman and Nicobar \\ ${ }^{2}$ Scientist D, Regional Medical Research Centre (ICMR), PB No. 13, Port Blair, Andaman and Nicobar \\ *Corresponding Author: Dr. I.P.Sunish, Division of Medical Entomology, Regional Medical Research \\ Centre, Andaman \& Nicobar Islands
}

\begin{abstract}
The susceptibility status of disease vectors, viz; Anopheles sundaicus and Aedes albopictus, against the insecticides used in public health need to be monitored at regular intervals, in order to target these vectors for effective control. In the island under study, viz, Car Nicobar, Anopheles sundaicus is the principal vector transmitting malaria parasite. Aedes aegypti and Ae. albopictus are reported to transmit dengue and chikungunya viruses. Since the latter mosquito species are highly prevalent in the area under study, susceptibility test for this species was determined. Susceptibility status of mosquitoes against DDT (4\%), Malathion (5\%), Fenitrothion (1\%) and deltamethrin (0.05\%) were investigated by the standard WHO susceptibility test kit. All the tested insecticides were susceptible to An. sundaicus, while for Ae. albopictus, DDT and fenitrothion were resistant. The resistance may be due to the extensive usage of these insecticides. Even though DDT is regularly used as indoor residual spray bi-annually for the control of malaria, An. sundaicus was found susceptible to DDT, may be partly due to their exophilic nature, which prevent them from contact to the sprayed surfaces. More thorough investigation need to be carried out to determine the bionomics of this mosquito, in view of the declining trend of malaria in this island.
\end{abstract}

Keywords: insecticide, Anopheles sundaicus, Aedes albopictus, Andaman \& Nicobar Islands

\section{INTRODUCTION}

In Andaman and Nicobar Islands, malaria parasite is principally transmitted by Anopheles sundaicus, which is prevalent throughout the archipelago. On the basis of ecoethologic differences and isolation of populations on the coastal areas and islands of Southeast Asia, An. sundaicus was hypothesized to represent a complex of species [1,2]. This mosquito species is currently regarded as a complex of four species that do not reveal ecological differences such as freshwater/brackish water preference [3]. Cytogenetic studies of An. sundaicus in this island revealed the existence of cytotype D [4]. Due to its ecologic and behavioral plasticity, An. sundaicus has adapted to a range of coastal and inland environmental situations. The main requirement is the presence of sunlit breeding sites with fresh or brackish water, floating algae, and non-invasive vegetation in coastal areas and on islands.

Anopheles sundaicus is considered as either a major vector or secondary vector of malaria depending on region and country [5]. It has been regarded as the principal vector in coastal areas of India [1]. However, this species seem to have disappeared from the coastal belt of Orissa, India [6], probably be due to profound ecologic and salinity changes. Presently, the species is restricted to Andaman \& Nicobar Islands [3], and is the principal vector of malaria. Aedes aegypti and Ae. albopictus are reported to transmit dengue and chikungunya viruses. However, Ae. albopictus was observed to be widespread in Car Nicobar Island [7], and is considered as the vector transmitting both dengue and chikungunya viruses. There are reports of these viruses circulating among the local inhabitants of this island [8].

Among the available vector control interventions, indoor residual spraying (IRS) of insecticides and long-lasting insecticidal nets/ materials (LNs/LMs) are considered effective for limiting malaria transmission in disease control programmes. National Vector Borne Disease Control Program 
(NVBDCP) is the central nodal agency, which takes care of all major vector borne diseases in India, including Andaman and Nicobar islands. Two rounds (bi-annually) of indoor residual spraying using DDT is being carried out per year by the NVBDCP in all the houses of the village. The development of insecticide resistance in vector mosquitoes, viz, An. sundaicus and Ae. albopictus, which are prevalent in Car Nicobar island, need to be monitored at regular intervals. For An. sundaicus, there are no records for the past two decades, and those findings available showed variation in the susceptibility status. In 1978, the species was found to be resistant to DDT [9], while during 1989 and later in 1997, the species was found susceptible $[10,11]$.

In view of the above, the susceptibility status of the principal vector of malaria viz, An, sundaicus, and the vector of dengue, Ae. albopictus, in Car Nicobar Island, to various insecticides used in public health was investigated, in order to take mid-course corrections, if any.

\section{MATERIALS AND MeTHOdS}

Andaman and Nicobar Islands ( $92^{\circ}$ to $94^{\circ}$ East and $6^{\circ}$ to $14^{\circ}$ North) is an archipelago of 572 islands/islets, having an area of $8,249 \mathrm{~km}^{2}$. There are three districts in this archipelago, viz, , South Andaman, North \& Middle Andaman and Nicobar. Anopheline and Aedes mosquitoes were collected in different villages of Car Nicobar, which is the headquarters of the Nicobar group of Islands. The ten-degree channel separates Car Nicobar from Andaman Islands. In Car Nicobar, malaria cases have declined significantly during the past few years, and are attributed to the control measures being adopted by the malaria department. However, a cross sectional survey showed that the anopheline vector, An. sundaicus was prevalent in the island. Similarly, another study showed high prevalence of Ae. albopictus [7].

Adult insecticide susceptibility tests were conducted following WHO standard method by exposing field-collected population of mosquitoes to DDT (4\%), malathion (5\%), deltamethrin $(0.05 \%)$, fenitrothion (1\%) and their respective control papers [12]. Mosquitoes were collected during the early morning hours using a mouth aspirator and torch light. The mosquitoes collected from field were held in a cloth cage with a wet towel around the cage and brought to the base laboratory. The species were identified based on morphological characters using a standard identification key for anophelines [13] and for culicines [14]. Mosquitoes were exposed for a period of one hour followed by $24 \mathrm{~h}$ holding period at $27 \pm 2{ }^{\circ} \mathrm{C}$ temperature and $70-80 \%$ relative humidity using a carton lined with moist towel/filter papers at the bottom. At least 3-4 test replicates were used in the tests against the given insecticide and two replicates to respective control papers. Mortality was determined by scoring the dead and alive mosquitoes at the end of $24 \mathrm{~h}$ holding period and results were expressed as percent mortality. Test mortality was corrected by applying Abbott's formula [15], when control mortality was recorded between 5 and $20 \%$, while tests with $>20 \%$ control mortality were discarded. The susceptibility test results were interpreted following WHO recommendations [16]. Briefly, mosquitoes were considered to be susceptible if the percentage of mortality was in the range 98-100 $\%$, and a mortality of less than $98 \%$ was suggestive of the existence of resistance.

\section{RESULTS AND DISCUSSION}

The WHO diagnostic dosage kit is the most reliable and easy method to determine the susceptibility status of vector mosquitoes against various insecticides used in public health [17]. Therefore, as there is lack of updated information on the susceptible baselines and diagnostic dosages, insecticide susceptibility status of An. sundaicus and Ae. albopictus was determined using a standard WHO susceptibility test kit for three major classes of insecticides designated for mosquito species.

Adult bioassay results indicated complete susceptibility of An. sundaicus mosquitoes to DDT (4\%), malathion (5\%), fenitrithion (1\%) and deltamethrin (0.05\%), as the mortality obtained was above 98 percent (Table 1). However, susceptibility profile for Ae. albopictus showed that the species was susceptible to malathion and deltamethrin; while resistant to DDT and fenitrothion (95\% and 80\% mortality respectively). Malathion in Car Nicobar island has been generally used in fogging operations during outbreaks of vector-borne diseases and also during the period of high density. In Assam also, Ae. albopictus was susceptible to malathion [18]. Resistance to DDT could have developed due to prolonged use in vector control programmes for over five decades in these islands. In Thailand, DDT for the control of dengue vector had led to the development of resistance to this insecticide, in a short period of two years [19]. Kdr mutation of voltage-gated sodium channel may be 
A Note on the Insecticide Susceptibility Status of Disease Vectors; Anopheles sundaicus and Aedes albopictus, in the Car Nicobar Island

responsible for the resistance to DDT, in addition to the detoxifying enzyme activity [20]. Resistance to fenitrothion for Ae. albopictus has also been observed earlier from other parts of Andaman and Nicobar archipelago [21].

Table 1. Susceptibility status of An. sundaicus and Ae. albopictus adults to insecticides

\begin{tabular}{|c|c|c|c|c|}
\hline \multirow[b]{2}{*}{ Insecticide (Conc.) } & \multicolumn{2}{|c|}{ Anopheles sundaicus } & \multicolumn{2}{|c|}{ Aedes albopictus } \\
\hline & $\begin{array}{l}\text { Number } \\
\text { exposed }\end{array}$ & $\begin{array}{l}\text { Corrected } \\
\text { mortality }(\%)\end{array}$ & Number exposed & $\begin{array}{l}\text { Corrected } \\
\text { mortality }(\%)\end{array}$ \\
\hline DDT (4\%) & 60 & \multirow{2}{*}{100} & 60 & \multirow{2}{*}{$95 *$} \\
\hline Control & 20 & & 20 & \\
\hline Malathion (5\%) & 60 & \multirow{2}{*}{100} & 80 & \multirow{2}{*}{100} \\
\hline Control & 20 & & 20 & \\
\hline Fenitrothion (1\%) & 60 & \multirow{2}{*}{100} & 80 & \multirow{2}{*}{$80 *$} \\
\hline Control & 20 & & 20 & \\
\hline Deltamethrin $(0.05 \%)$ & 60 & \multirow{2}{*}{100} & 80 & \multirow{2}{*}{100} \\
\hline Control & 20 & & 20 & \\
\hline
\end{tabular}

*Resistant to insecticide (<98\% mortality)

Even though DDT is being used widely by the malaria control programme in Car Nicobar island, as an indoor residual spray, the malaria vector, An. sundaicus was found to be susceptible. The species was also found susceptible to other insecticides tested. Possibly, the vector could have changed its behaviour to exophilism, thus avoiding contact with the sprayed surfaces. A thorough investigation need to be carried out to determine the resting and feeding behaviour of these mosquitoes in the context of insecticide usage, in order to target them for effective control. Susceptibility status of $A n$. sundaicus to various insecticides in use has not been reported for the past two decades. Hence, this paper represents the updated information of the same which is significant, in view of the declining trend of malaria in Car Nicobar island, and also in the archipelago as a whole.

\section{REFERENCES}

[1] Rao, T.R. The Anophelines of India. Malaria Research Centre (ICMR), Delhi. p 518. (1984)

[2] Subbarao. Anopheline Species Complexes in South and South-East Asia. World Health Organization, SERO Technical Publication No. 57; pp: 102. (2007)

[3] Alam, M.T., Das, M.K., Ansari, M.A. and Sharma, Y.D. Molecular identification of new sibling species of human malaria vector Anopheles sundaicus from Andaman and Nicobar islands of India. Acta Trop 1738: 1-9. (2005)

[4] Nanda, N., Das, M.K., Wattal, S., Adak, T. and Subbarao, S.K. Cytogenetic characterization of Anopheles sundaicus (Diptera: Culicidae) population from Car Nicobar Island, India. Ann Entomol Soc Am 97: 171176. (2004)

[5] Dusfour, I., Harbach, R. E. and Manguin, S. Bionomics and systematics of the Oriental Anopheles sundaicus complex in relation to malaria transmission and vector control. Am. J. Trop. Med. Hyg. 71(4): 518-24. (2004)

[6] Dash, A.P., Hazra, R.K., Mahapatra, N. and Tripathy, H.K. Disappearance of malaria vector Anopheles sundaicus from Chilika Lake area of Orissa State in India. Med Vet Entomol 14: 445-449.(2000)

[7] Sunish, I.P., Shriram, A.N., Arun, S. and Vijayachari, P. Spatio-temporal distribution of Aedes mosquitoes in Car Nicobar Island: implication in the transmission of arboviruses. J Asia Pac Entomol 17:761-766. (2014)

[8] Chaaithanya, I.K., Bhattacharya, D., Muruganandam, N. et al. Dengue: a newly emerging viral infection in Andaman and Nicobar Islands, India. Epidemiol Infect 140:1920-1924. (2012)

[9] Kalra, N.L. National Malaria Eradication Programme, India - its problems, management and research needs. J Commun Dis 10: 1-20. (1978)

[10] Das, S.C., Nath, D.R., Bhuyan, M., Das, N.G., Baruah, I. and Talukdar, P.K. Studies on malaria and filariasis vectors in Kamorta and Great Nicobar Islands. Indian J Malariol 26: 153-157. (1989)

[11] Nagpal, B.N. and Kalra, N.L. Malaria vectors of India. J Parasitic Dis 21: 105-112. (1997) 
A Note on the Insecticide Susceptibility Status of Disease Vectors; Anopheles sundaicus and Aedes albopictus, in the Car Nicobar Island

[12] World Health Organization. Test procedures for insecticide resistance monitoring in malaria vectors. Bioefficacy and persistence of insecticides on treated surfaces. Report of the WHO informal consultation. Geneva.. WHO/CDC/MAL/98.12. p. 46 (1998)

[13] Nagpal, B.N. and V.P. Sharma. Indian Anophelines. Oxford \& IBH Publishing Co. Pvt. Ltd. India. Pp.416. (1995)

[14] Barraud, P.J. The Fauna of British India Including Burma and Ceylon. Diptera: Culicidae, Tribes Megarhinini and Culicini, vol. V. Taylor and Francis, London, pp. 1-452.(1934)

[15] Abbott, W.S. A method of computing the effectiveness of an insecticide. J Econ Entomol; 18: $265-7$. (1925)

[16] World Health Organization. Test procedures for insecticide resistance monitoring in malaria vector mosquitoes. ISBN: 9789241505154 (2013)

[17] Ferrari, J.A. Insecticide resistance In: The biology of disease vectors. Beaty BJ and Marquardt WC (eds). University Press of Colorado, Niwot, Colorado, (1996) pp: 512-529.

[18] Dhiman, S., Rabha, B., Yadav, K., Baruah, I. and Veer, V. Insecticide susceptibility and dengue vector status of wild Stegomya albopicta in a strategically important area of Assam, India. Parasit Vectors 7:295 (2014)

[19] Gratz, N.G. Lessons of Aedes aegypti control in Thailand. Med Vet Entomol 7:1-10 (1993)

[20] Chareonviriyaphap, T., Bangs, M.J., Suwonkerd, W. et al. Review of insecticide resistance and behavioral avoidance of vectors of human diseases in Thailand. Parasit Vectors 25:6-280. (2013)

[21] Arun Sivan, A. N. Shriram, I. P. Sunish and P. T. Vidhya. Studies on insecticide susceptibility of Aedes aegypti (Linn) and Aedes albopictus (Skuse) vectors of dengue and chikungunya in Andaman and Nicobar Islands, India. Parasitol Res (2015) 114:4693-4702 (2015)

Citation: Z. A. Khan, I. P. Sunish, "A Note on the Insecticide Susceptibility Status of Disease Vectors; Anopheles sundaicus and Aedes albopictus, in the Car Nicobar Island ", International Journal of Research Studies in Zoology, vol. 3, no. 4, p. 50-53, 2017. http://dx.doi.org/10.20431/2454-941X.0304007

Copyright: () 2017 Authors. This is an open-access article distributed under the terms of the Creative Commons Attribution License, which permits unrestricted use, distribution, and reproduction in any medium, provided the original author and source are credited. 